\title{
Asthma diagnosis and treatment - 1015. Improvements in lung function in an indian population with IgE mediated asthma receiving omalizumab in a real-world setting
}

\author{
Randeep Guleria ${ }^{1 *}$, Deepak Talwar ${ }^{2}$, Ashok Mahashur ${ }^{3}$, Mangala Kotnis ${ }^{4}$ \\ From 2nd WAO International Scientific Conference (WISC 2012) \\ Hyderabad, India. 6-9 December 2012
}

\section{Background}

Omalizumab is a recombinant humanized anti-IgE monoclonal antibody, indicated for add-on therapy for moderate- to severe-persistent allergic (IgE-mediated) asthma. Interim results at the 16 weeks time point of this 52 week study have previously been presented. We present a subgroup analysis looking at the efficacy of omalizumab at 16 weeks in relation to the serum IgE levels at baseline.

\section{Methods}

This open-label, multi-center, observational, prospective study, recruited 72 patients with moderate-to-severe persistent allergic asthma. Clinical efficacy was evaluated on the basis of improvement in asthma exacerbations, days missed at work/college, hospitalizations, ACQ 5, ACT scores, and FEV1. Safety and tolerability were also assessed. Qualitative and quantitative variables are analyzed using Chi-Square tests and paired t-tests, respectively. All parameters are comparing results at week 16 of omalizumab treatment with those at baseline.

\section{Results}

Mean serum-IgE levels at baseline were $437.45 \mathrm{kIU} \mathrm{L-1}$ (range 32-1599 kIU L-1). For analysis purposes patients were categorized into three groups, according to their baseline serum-IgE levels. Group $1(n=31)$, comprised patients with baseline serum-IgE levels of 32-250 kIU $\mathrm{L}-1)$, and in group $2(\mathrm{n}=24)$ and $3(\mathrm{n}=17)$, patients with baseline serum-IgE levels of 251-600 and >600 kIU L-1; respectively. Mean (SD) age in three groups was 53.5
(9.6), 43.8 (15.3) and 60.5 (13.5) years; correspondingly. In group $1, \mathrm{FEV} 1$ levels improved by 0.27 liters ( 0.88 vs. $1.15,95 \% \mathrm{CI} ; \mathrm{p}=0.000)$ and in group 2 and 3 by 0.67 liters $(1.32$ vs. $2.00,95 \% \mathrm{CI} ; \mathrm{p}=0.001)$ and by 0.55 liters (1.27 vs. $1.46,95 \% \mathrm{CI} ; \mathrm{p}=0.002)$; respectively. Improvement in FEV1 levels was more prominent amongst patients with serum-IgE levels $>600 \mathrm{kIU} \mathrm{L}-1$. This change in FEV1 levels in 3 groups, was significantly different, as determined by one-way ANOVA $(\mathrm{F}(2,23)=7.959, \mathrm{p}=0.002)$.

\section{Conclusion}

In these patients add-on therapy with omalizumab improved lung function, quality of life and other clinical measures. In this small sub group analysis, the improvement was more marked in patients with a higher IgE level at baseline.

\section{Author details}

'Department of Pulmonary Medicine and Sleep Disorders, All India Institute of Medical Sciences, India. ${ }^{2}$ Chest Medicine, Metro Hospital, Noida, India. ${ }^{3}$ Chest Medicine, P.D.Hinduja National Hospital, India. ${ }^{4}$ Medical Advisor, Novartis India Limited, India.

Published: 23 April 2013

\section{doi:10.1186/1939-4551-6-S1-P15}

Cite this article as: Guleria et al:: Asthma diagnosis and treatment 1015. Improvements in lung function in an indian population with IgE mediated asthma receiving omalizumab in a real-world setting. World Allergy Organization Journal 2013 6(Suppl 1):P15. 